\title{
La Tour Blanche, Issoudun
}

$n^{\circ} 068637$

Simon Bryant

\section{(2) OpenEdition}

Journals

Édition électronique

URL : http://journals.openedition.org/adlfi/13638

ISSN : 2114-0502

Éditeur

Ministère de la culture

Référence électronique

Simon Bryant, «La Tour Blanche, Issoudun », ADLFI. Archéologie de la France - Informations [En ligne] Centre, mis en ligne le 24 octobre 2014, consulté le 03 mai 2019. URL : http:// journals.openedition.org/adlfi/13638

Ce document a été généré automatiquement le 3 mai 2019.

(c) Ministère de la Culture et de la Communication, CNRS 


\section{La Tour Blanche, Issoudun}

$n^{\circ} 068637$

Simon Bryant

Lien Atlas (MCC) : http://atlas.patrimoines.culture.fr/atlas/trunk/index.php?

ap_theme=DOM_2.01.02\&ap_bbox=1.931;46.909;2.085;46.981

1 La Tour Blanche se situe dans la partie sud-est de la ville d'Issoudun, sur une butte sans doute rehaussée artificiellement. Elle était intégrée dans le système défensif de la ville, situation aujourd'hui difficile à apprécier à cause des transformations du tissu urbain. Bien sûr, elle a déjà fait l'objet de nombreuses études historiques, mais l'analyse présentée ici résulte d'un projet de restauration et de mise en valeur, qui a nécessité l'exécution de relevés pour la constitution du dossier de l'architecte en chef des Monuments Historiques. Il ne s'agit donc pas de réécrire l'histoire de ce monument notoire, mais de mettre à disposition des données (relevés et descriptions archéologiques) qui n'avaient pas trouvé leur place dans les publications antérieures.

2 La construction de la tour se situe entre 1194 (prise d'Issoudun par Marchader) et 1202, date de son achèvement par Philippe. La rapidité de son exécution peut expliquer l'homogénéité de l'édifice. Elle a été construite sur une structure antérieure dont une partie des vestiges est toujours visible au nord. Notons que l'aménagement du site et des fouilles ont entrainé la destruction partielle de l'émottement de la base de la tour, ainsi que de son fruit. Celui-ci avait une hauteur de $4 \mathrm{~m}$ pour une épaisseur de $2 \mathrm{~m}$. Il était donc beaucoup moins facile de circuler au pied de la tour. A l'intérieur, la tour se divise en 3 niveaux : le rez-de-chaussée, le premier étage avec sa salle voûtée, et le deuxième étage. Des trous de boulin, au sommet à l'extérieur, attestent l'existence d'un hourdis en bois avec une toiture. Les vestiges au pied de la tour seraient ceux d'une chapelle romane.

3 La construction de la tour a entraîné la destruction partielle d'un édifice antérieur dont les vestiges sont toujours visibles sur le côté nord, et qui a été fouillé en 1847. Les relevés d'alors par Pérémé et l'architecte Dumoutet donnent une vue assez complète de l'état de la structure lors de sa découverte. En revanche, aucun rapport n'a été remis à l'issue de la 
fouille entreprise en 1982, ce qui nous prive des renseignements sur les structures enfouies, les niveaux de sol et leur datation. D'abord interprétés comme ceux d'une basilique paléo-chrétienne, les vestiges représentent plutôt les restes d'une chapelle ou d'un oratoire du XI ${ }^{\mathrm{e}} \mathrm{s}$.

4 L'ensemble est composé d'un édifice, probablement une chapelle ou un oratoire, enfermé à l'est par une forte enceinte triangulaire d'une largeur interne de $8,70 \mathrm{~m}$ ou $12,20 \mathrm{~m}$ (externe). Les deux autres côtés, de 7,20 m de longueur à l'intérieur, sont composés par un mur d'1,40 m d'épaisseur. Pérémé avait remarqué la présence d'une structure circulaire contenant un bassin carré d'une profondeur de $1 \mathrm{~m}$ environ. Interprétée comme étant une citerne, sa faible profondeur évoque plutôt une fontaine, peut-être même une cuve baptismale. La chapelle est constituée d'une simple nef en forme de trapèze, orientée est-ouest, d'une longueur interne de 6,80 $\mathrm{m}$ sur une largeur interne de $6,50 \mathrm{~m}$ à l'ouest et de $6 \mathrm{~m}$ à l'est. Son angle sud-ouest se trouve sous la tour. L'abside était éclairée par une fenêtre centrale, légèrement embrasée. Elle était flanquée à l'extérieur par 2 contreforts, et à l'intérieur, elle était marquée par un arc en plein cintre reposant sur 2 colonnes, aujourd'hui disparues. Elle était flanquée par 2 chapelles latérales. Au sud, on observe un grand couloir aveugle de 7,80 $\mathrm{m}$ de longueur sur 1,40 $\mathrm{m}$ de largeur dont la fonction reste obscure.

5 Le mur de l'enceinte est exclusivement réalisé d'un petit appareillage de moellons de calcaire à assises régulières. La chapelle a été construite avec un appareil mixte : tous les montants des ouvertures, des baies et des contreforts sont en pierre de taille de calcaire tandis que le reste est en petit appareil de moellons de calcaire. Les claveaux des arches sont de petite taille (de 16 à $20 \mathrm{~cm}$ de longueur sur une largeur d'environ $12 \mathrm{~cm}$ à l'intrados) et présentent des traces de taille très fines en chevrons ou en arêtes de poisson. Un grand nombre des blocs présentent des trous de louve, ce qui suggère une origine antique. La régularité et la taille des moellons conforte cette impression, qui certifie que des structures antiques ont été utilisées comme carrière pour sa construction, et ce dans des proportions qui pourraient être très élevées. La proximité de ruines galloromaines est attestée par la découverte de grands blocs architectoniques dans la rue Notre-Dame au xix ${ }^{\mathrm{e}} \mathrm{s}$. et près de la rue Nouvelle du Château lors de fouilles récentes (cf. BSR 1994 : 63-66).

6 Les relations entre la chapelle et le mur nord de l'enceinte triangulaire ne sont pas claires. En plan, il semblerait que l'ensemble soit homogène mais les différences entre la maçonnerie de la chapelle et celle de l'enceinte évoquent la possibilité de 2 phases de construction. Il est possible que le mur nord de l'enceinte ait englobé celui de la chapelle : son parement interne semble s'appuyer contre elle, mais sans lui être chaîné. Cette hypothèse ne pourra être vérifiée qu'après un nettoyage poussé de ce secteur, voire un sondage dans les parements.

7 La construction de la tour et ses dispositions internes ont été amplement décrites ailleurs, et il n'est ici nécessaire que d'ajouter une mention sur le programme du décor intérieur de la salle voûtée. Elle a été enduite et décorée de faux joints rouges sur un fond blanc. L'intrados des ouvertures et de la voûte, ainsi que les murs à partir du niveau de la naissance des arcs formerets, sont peints en noir sur fond blanc: les "assises" ont une hauteur de 22 à $23 \mathrm{~cm}$ et les "blocs" ont environ de 50 à $55 \mathrm{~cm}$ de long. Un autre décor, sous la forme de graffiti, rappelle que cette tour était habitée et a même servi de prison pendant le Moyen Âge et l'époque moderne. La quantité et souvent la qualité des images sont impressionnantes : hormis des armoiries, il faut relever une scène de joute, un Saint- 
Georges terrassant le dragon, une demoiselle en détresse, et surtout la silhouette d'une femme enceinte qui est une représentation exceptionnelle d'un sujet féminin. Plusieurs inscriptions hébraïques, étudiées par ailleurs, attestent également la persécution des juifs au début du XIV ${ }^{\mathrm{e}} \mathrm{s}$.

INDEX

Index géographique : Centre, Indre (36), Issoudun (36088)

Index chronologique : Moyen Âge, Temps Modernes

operation Sondage (SD)

Mots-clés : chapelle, enceinte 